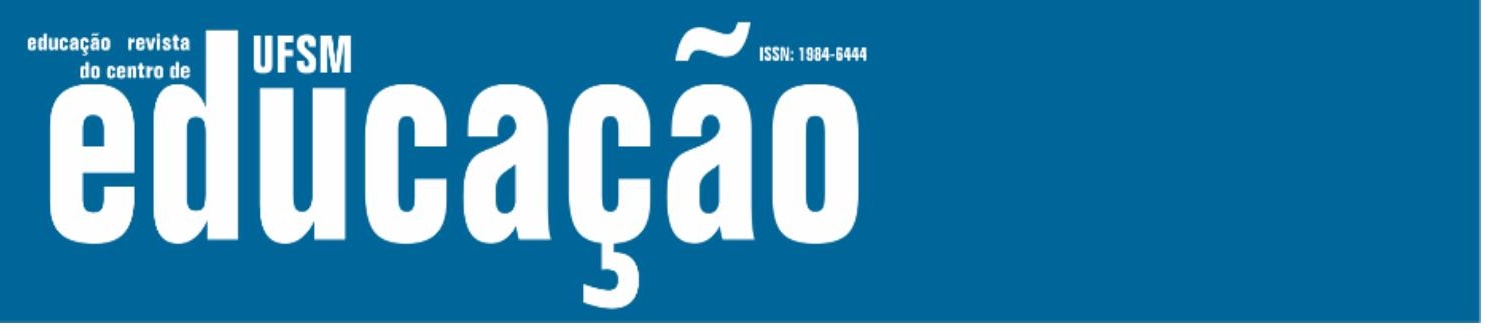

ISSN: 1984-6444 | http://dx.doi.org/10.5902/1984644439190

\title{
Educação intercultural e Lócus de enunciação: Inspirado em uma experiência educativa no México
}

\author{
Intercultural education and Locus of Enunciation: Inspired in an \\ educational experience in Mexico
}

Lucilene Julia Da Silva

Professora doutora pesquisadora Independente e Pesquisadora do Grupo de Pesquisa Educação e Interculturalidade. Universidade Católica Dom Bosco, Campo Grande, Mato Grosso do Sul, Brasil. lucilenejulia12@gmail.com - http://orcid.org/0000-0003-4460-7333

Adir Casaro Nascimento

Professora doutora na Universidade Católica Dom Bosco, Campo Grande, Mato Grosso do Sul, Brasil. adir@ucdb.br - http://orcid.org/0000-0002-7488-6022

Maria Bertely Busque

Doutora em Antropologia Social. Professora e Ingestigadora.

bertely@ciesas.edu.mx

Recebido em 23 de julho de 2019

Aprovado em 08 de janeiro de 2021

Publicado em 10 de março de 2021

\section{RESUMO}

O presente artigo aborda uma experiência político-educativa vivida no México e que corresponde a reflexões de questões emergentes de processos formativos de professores indígenas. Estes processos sugerem correlações da interculturalidade crítica com o bem viver, da decolinialidade do saber e do poder e das políticas epistêmicas. Essa experiência formaliza-se no projeto de pesquisa intitulado "Milpas Educativas: Laboratorios socionaturales vivos para el buen vivir". Ele é capitaneado pelos membros integrantes da Red de Educación Inductiva Intercultural (REDIIN) no interior do Centro de Investigaciones y Estudios Superiores en Antropología Social (CIESAS) e da Universidad Iberoamericana (UIA), em parceria com a Unión de los Maestros para una Nueva Educación en México (UNEM/EI). O objetivo é analisar como circularam algumas enunciações sobre o campo de estudos da educação intercultural que formou significados observados nesses espaços formativos, especificamente no projeto de pesquisa. A metodologia usa a perspectiva de lócus de enunciação para explicar uma aproximação analítica conjugada com as concepções do método indutivo intercultural e do pensamento decolonial, para entender como a interculturalidade crítica reverbera em três encontros ocorridos e pertinentes a cinco estados mexicanos, quais sejam: Chiapas, Yucatán, Puebla, Oaxaca e Mochoacán, em 2017. A investigação indica que as repercussões foram conduzidas para um 


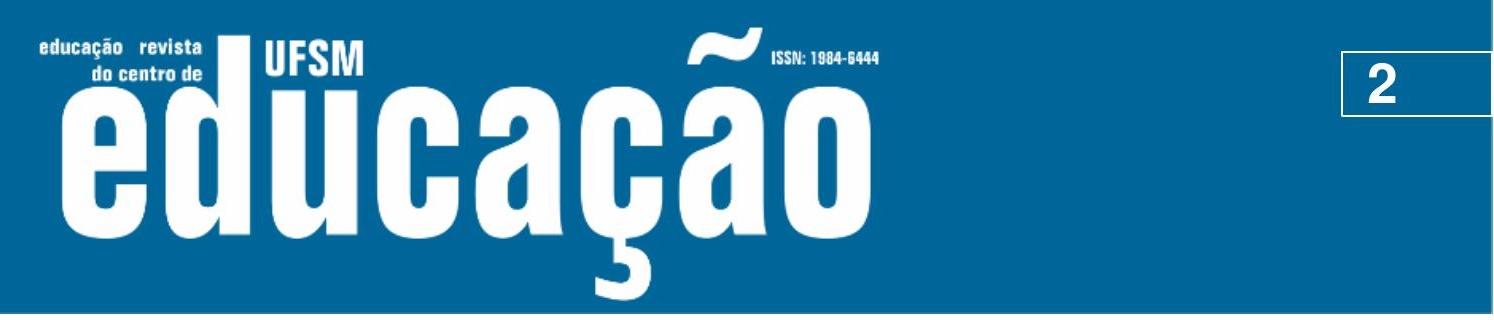

ISSN: 1984-6444 | http://dx.doi.org/10.5902/1984644439190

processo formativo que procurou compreender distintas dimensões que caracterizaram a interculturalidade e apresentaram indícios nessa formação de pensamentos e práticas contra-hegemônicos. O estudo aponta para uma abertura de novos horizontes de aprendizados e para uma possível elaboração da proposta que denominamos de Política de Resistência.

Palavras-chave: Educação intercultural de formação de professores indígenas; Lócus de enunciação nas comunidades indígenas; Outros espaços e experiências formativos no México.

\section{ABSTRACT}

This paper addresses a political and educational experience that took place in Mexico and corresponds to reflections on some emerging questions of indigenous teacher training processes. These processes suggest correlations of critical interculturality with the good living, decoloniality of knowledge and power, and epistemic policies. This experience is present in the ongoing research project Milpas Educativas: Laboratorios socionaturales vivos para el buen vivir. This project is led by the members of Red de Educación Inductiva Intercultural (REDIIN), part of the Centro de Investigaciones $y$ Estudios Superiores en Antropología Social (CIESAS) and of Universidad Iberoamericana (UIA), with the Unión de los Maestros para una Nueva Educación en México (UNEM/EI). It seeks to analyze how some studies in the field of intercultural education have circulated, which has created meanings noted in those training spaces, particularly in the research project. Its methodology is based on a locus of enunciation perspective to explain an analytical approximation coupled with the intercultural inductive method and decolonial thinking conceptions and to understand how the critical interculturality have reverberated in three meetings considering five Mexican states in 2017, namely, Chiapas, Yucatán, Puebla, Oaxaca e Mochoacán. The study conducted suggests the repercussions were led to a training process aiming to understand different aspects that characterize interculturality and present clues in this creation of counter-hegemonic thinking and practices. The study also points to the openness of new learning horizons and a possible elaboration of the proposal we have called Resistance Policy.

Keywords: Intercultural education of indigenous teacher training; Locus of enunciation in indigenous communities; Other Spaces and training experiences in Mexico. 


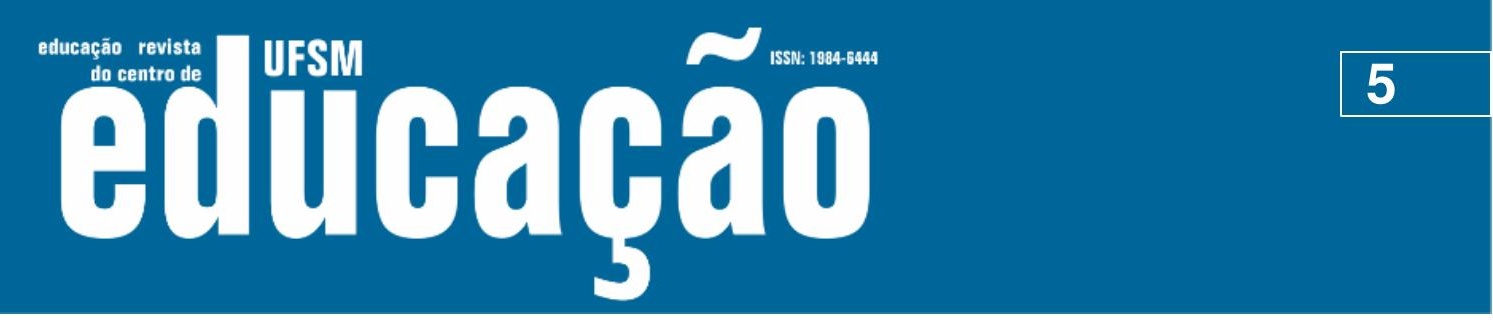

ISSN: 1984-6444 | http://dx.doi.org/10.5902/1984644439190

muitos desses professores-formadores da UNEM/El têm mais de 20 anos de experiência com o Método aqui apresentado, especialmente, do povo Maya, em projetos de pesquisa que são associados ao CIESAS ${ }^{9}$.

Para um melhor entendimento do que estamos tratando, o projeto 'Milpas Educativas: Laboratorios socionaturales vivos para el buen vivir: congrega o objetivo de que as:

\begin{abstract}
Milpas Educativas difundem e fortalecem valores associados ao 'bem viver' de cada comunidade e povo, assim como seus conhecimentos, habilidades e técnicas, fomentados pelo processo de 'alfabetização territorial ${ }^{10}$, ecológica e natural' articulados na educação escolar. Que são impulsionados nos territórios socionaturais, como, hortas escolares, comunitárias, familiares. Enfim, essas Milpas são espaços educativos a partir de uma visão sintática da cultura e dos indicadores [do Método Indutivo Intercultural] provindas das atividades sociais. [...] Elas se vinculam ao fazer pedagógico, efetuando atividades didáticas, nas diferentes modalidades escolares, fundadas na interaprendizagem entre indígenas e não indígenas (BERTELY, 2015, p. 1. Tradução livre)
\end{abstract}

E mais:

[...] é um projeto colaborativo dirigido a construir um modelo pedagógico intercultural multilíngue para crianças (e todas as pessoas interessadas) de diversas regiões do país. O projeto busca responder os desafios do sistema educativo em contextos indígenas ao desenvolver as atividades pedagógicas a partir de das atividades sociais das comunidades participantes.[...] com colaboração de membros da comunidade, crianças indígenas, educadores comunitários, professores oficiais, acadêmicos e científicos de diferentes instituições que geram processos educativos interculturais sustentados com - princípios do Bem Viver definidos pelas comunidades participantes que permitirão articular conhecimentos locais e escolares. A prática educativa alternativa resultante revalorizará e empoderará a sociedade indígena, confiando em suas capacidades e liberando sua criatividade. Por outro lado, geram aprendizagens interculturais úteis para a construção de uma vida boa em território socionatural comunitário, de acordo com os projetos sociais e plano de vida das famílias e comunidades participantes (EDUCAÇÃO FUTURA, 2017, n/p.).

Nessa corrente, Sartorello (2018) salienta que o projeto está envolto intrinsicamente com o trabalho que lança para a elaboração intercultural de políticas epistêmicas (a partir do que elas mesmas geram em consonância às articulações de concepções de outras tradições de conhecimentos). Entendemos essa posição quando escutamos sobre valorização, empoderamento e ativismo da sociedade indígena a que pertencem, ao darmos atenção ao que os professores mexicanos 


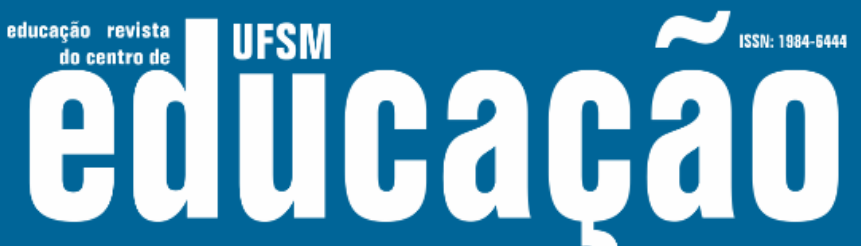

ISSN: 1984-6444 | http://dx.doi.org/10.5902/1984644439190

da interculturalidade, assim como as experiências em análise surgem e reagem em um contexto/ambiente sociocultural situado e contextualizado, e como observamos a comunicação nos encontros com grupos sociais de diferentes sociedades indígenas do México; sociedades essas que têm diferentes culturas, diferentes formas de pensar e compreender o mundo em que vivem e são rodeadas por conflitos de relações sociais que pode ter consequência também em relações interculturais. Essas divergências são originadas do lugar em que se instalam e da posição dos grupos sociais que adotam, e que requer negociações que possam rompê-lo, visando uma situação de alcance de objetivo comum (WALSH, 2009, 2010; QUIJANO, 2009).

Essa combinação metodológica que optamos, procura compreender e questionar outros modos de entender os enunciados dentro daquilo que vivenciamos nas experiências, de mudanças de rumo e acordo com o que foi realizado, não é dizer que o projeto não tenha um fio condutor, mas que essa condução não é fixa, pois, a cada encontro se debatem temas desencadeados nos temas anteriores ou nas práticas que estão experienciando, deste modo, enriquecendo os sentidos. Essa ideia está na linha de pensamento de Meyer e Paraíso (2014, p. 18-19) ao afirmarem que: "afastam-nos daquilo que é rígido, das essências, das convicções, dos universais, da tarefa de prescrever e de todos os conceitos e pensamentos que nos ajudem a construir imagens de pensamento para interrogar e descrever nosso objeto". As autoras ainda argumentam que essa trilha "movimentam-nos para impedir a 'paralisia' das informações que produzimos que precisamos descrever e analisar [...] Movimentamo-nos [...] para multiplicar sentidos, formas e lutas" (MEYER; PARAíSO, 2014, p. 18-19).

$E$, com isso, a provocação é suscitar a participação, a colaboração, a solidariedade e o aprendizado compartilhado entre os pesquisadores e as pessoas que contribuem com suas experiências nessa seara, construindo assim, espaços epistêmicos outros. 


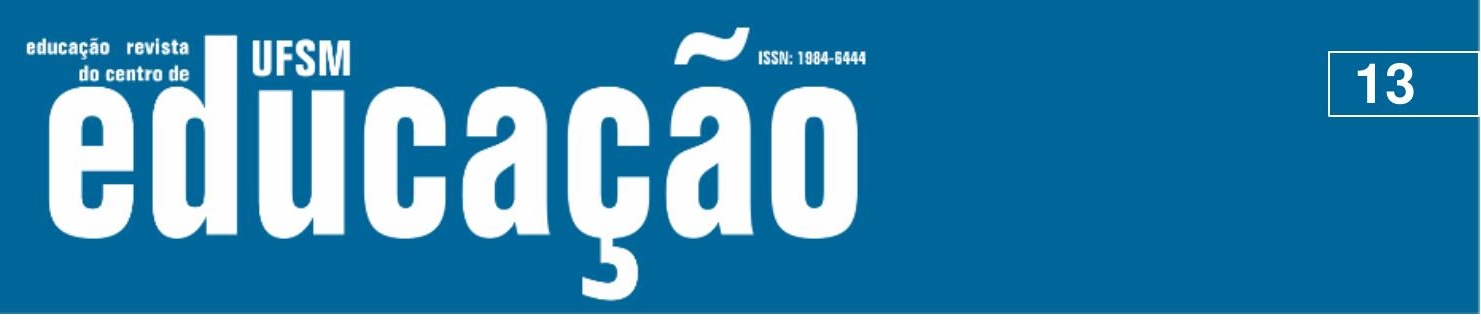

ISSN: 1984-6444 | http://dx.doi.org/10.5902/1984644439190

serão voltadas para processos político-educativos? Como se refletem os efeitos do capitalismo e neoliberalismo no que fazemos nas Milpas Educativas? Qual é o coração pulsante deste novo trabalho que estamos iniciando? Como já mencionado, devido ao projeto ainda estar em processo inicial, evidentemente os participantes ainda não tinham respostas para tais questionamentos, pois essas respostas viriam processualmente, em uma construção coletiva e colaborativa. Mesmo assim, consideramos válido colocálas aqui, porque o aprendizado é inconcluso, mesmo findando um projeto ou em outro lugar de enunciação, mas o referido processo nos inspirou a começar a pensar de outra forma.

b) Da visita Técnica na comunidade de Trancas, em Zoquitlán, Puebla, realizada no período de 05 a 09 de junho de 2017. Essa visita visava conhecer e participar das atividades sociais produtivas na horta escolar, presentes em duas escolas: uma do ensino da fase infantil e outra do restante do final do primeiro e segundo ciclos do ensino, sequencialmente: a) Centro de Educação Pré-Escolar Indígena (anos iniciais); b) Escola Vicente Sudiez (ensino fundamental, I e II). É importante dizer que nessas escolas, duas professoras fizeram formação pela formação nos diplomados nos anos de 2014 e 2015. Com base nessa formação as professoras colocaram em andamento algumas atividades nas suas práticas docentes com o apoio do MII. Nessa visita podemos experimentar a interaprendizagem por um professor-formador indígena, e uma pesquisadora não indígena, que participaram de uma reunião com os pais de família dos alunos das referidas escolas, autoridades do Comité Organizador da comunidade, e demais pessoas interessadas na exposição, cujo tema era a explicação com mais detalhes do conceito-metodológico e trabalho concreto com o Método Indutivo Intercultural e do trabalho, já que naquela comunidade as mesmas professoras assumiram um novo trabalho no seu fazer docente. Além disso, esclareceu-se que o novo trabalho no qual a comunidade estava se envolvendo era uma nova configuração do trabalho anterior, e que eram denominadas de Milpas Educativas, que oferecia mais potencialidade em trabalhar na horta das escolas, fazendo desse um lugar de 


\section{تutดaดูão}

ISSN: 1984-6444 | http://dx.doi.org/10.5902/1984644439190

Porquanto, essa proposta, em construção, arquiteta-se multifacetada e que faculta que essa temática nos situa num campo radicalmente novo ou ainda pouco explorado de estudo, em outros espaços de lugares enunciados, contornados na correlação de forças com posição hegemônica e de eurocentrismo.

Essas questões invocam seu lugar de enunciação para o re-existir, o insurgir, que se constrói em outras geografias políticas e educativas como, por exemplo, questionar a hegemonia do Norte/Global no continente latino-americano, e, consolidar as epistemologias do sul-sul. Isso é tematizado por Souza Santos e Menezes (2010, p. 19) que postulam a 'crise do paradigma epistemológico' e na 'ecologia dos saberes', essas duas categorias para os autores "foi também uma dominação epistemológica, uma relação extremamente desigual de saber-poder". Nesse sentido, convida-nos a um diálogo proposto nos questionamentos da corrente de pensamento decolonial, que pode abrir a possibilidade de se ter uma chave de leitura para entender de fato e superar o projeto colonial que enraizou nos povos colonizados que carregam ainda herança e uma ferida aberta em sua vida, que podemos ver por meio do contexto sociocultural situado e contextualizado (SOUZA SANTOS; MENEZES, 2010, p. 19; WALSH, 2009).

Talvez nossas observações aqui apresentadas, afigurem uma ideia compreensível de não definir a interculturalidade como algo que aparece tangível, e aqui questionamos: podemos conceber que a interculturalidade é somente tangível? Essa interrogativa pode indicar que a interculturalidade pressupõe distintos horizontes, e, supomos que ela acontece a partir do contexto situado e contextualizado.. Assim, interculturalidade é elaborada de forma teórica e prática tão somente na desde o seu lugar de enunciação que formula um grupo social , por meio de uma dinâmica própria que faz parte de cada lugar e que desenvolvem aprendizados singulares. Portanto, para este estudo são neles lugares e com essas dinâmicas que a interculturalidade ganha sentido, significado e lugar de fala, enfrentando e confrontando a correlação de forças dominantes e contra-hegemônicas. E com tais formulações se expande para outros lugares múltiplos, como nos processos e possibilidades na educação intercultural e na sociedade, de modo geral, de tal maneira, que possamos considerá-la uma educação intercultural. 


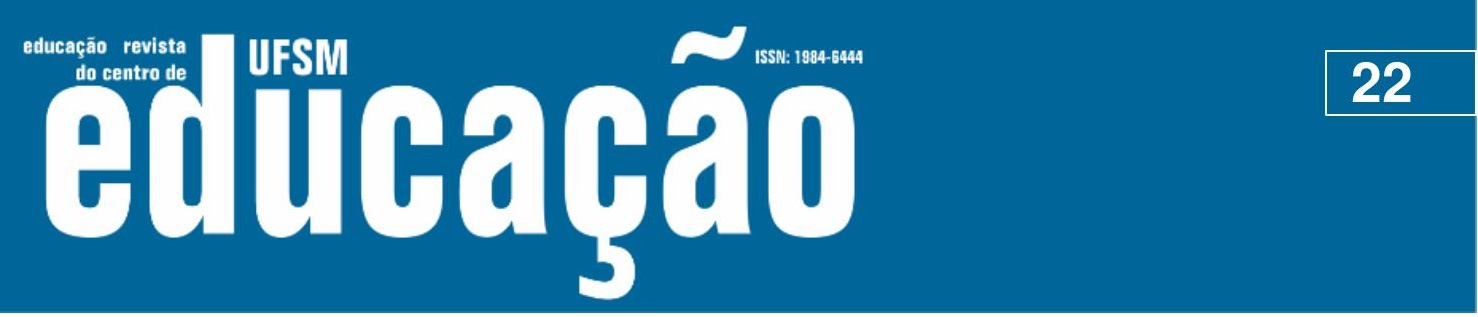

ISSN: 1984-6444 | http://dx.doi.org/10.5902/1984644439190

\section{Referências}

BERTELY, Maria. (Coord.). Educación, derechos sociales y equidad. T.I Educación y diversidad cultural, educación y medio ambiente, Colección: La investigación educativa en México, 1992-2002, 2003. p. 3-37.

BERTELY, Maria. Notas do Projetos das Milpas Educativas. 2015. REDIIN (Tradução nossa).

BHABHA, Homi. O local da cultura. 2. ed. Belo Horizonte: Editora UFMG, 2013.

DA SILVA, Lucilene Julia. As contribuições do Método Indutivo Intercultural para a construção da Escola Indígena Diferenciada. 2016. Tese (Doutorado em Educação, Conhecimento e Inclusão Social) - Faculdade de Educação, Universidade Federal de Minas Gerais, Belo Horizonte.

EDUCAÇÃO FUTURA. Sembrando Milpas Educativas: Laboratorios socionaturales vivos para el Buen Vivir. 2017. Disponível em: http://www.educacionfutura.org/milpas-educativas-educar-para-lainterculturalidad/.Acesso: 21 de maio 2019.

GASCHÉ. Jorge. (2008a). Niños, maestros, comuneros y escritos antropológicos como fuentes de contenidos indígenas escolares y la actividad como punto de partida de los procesos pedagógicos interculturales: Un modelo sintáctico de cultura. In: GASCHÉ, Jorge; BERTELY BUSQUETS, Maria; PODESTA, Rosanna. (Coords.). Educando en la diversidade: Investigaciones y experiências educativas interculturales y bilingües. Quito: AbyaYala, CIESAS, IIAP, 2008a.

GASCHÉ. Jorge. (2008b) Las motivaciones políticas de la educación intercultural indígena. ¿Hasta dónde abarca la interculturalidad? In: GASCHÉ, Jorge; BERTELY BUSQUETS, Maria; PODESTA, Rosanna (Coords.). Educando en la diversidade: Investigaciones y experiências educativas interculturales y bilingües. Quito y México: Editorial AbyaYala y CIESAS, 2008b.

MACAS, Luis. El Sumak Kawsay. Yachaykuna, Quito, n.13, p. 13-39, junio. 2010.

MELLEIRO, Marta Maria; GUALDA, Dulce Maria Rosa. Explorando a "fotovoz" em um estudo etnográfico: uma estratégia de coleta de dados. Rev Bras Enferm. v.58, n.2, p.191-3, mar-abr. 2005.

MEYER, Dagmar Estermann; PARAíSO, Marlucy Alves. (Orgs.). Metodologia de pesquisas pós-críticas em educação. 2.ed. Belo Horizonte: Mazza Edições, 2014.

PEREZ, G. Cambio cultural inducido. In: HOUTART. Cambios de las culturas. Bogotá: Ediciones desde abajo, 2016. p. 49-60. 


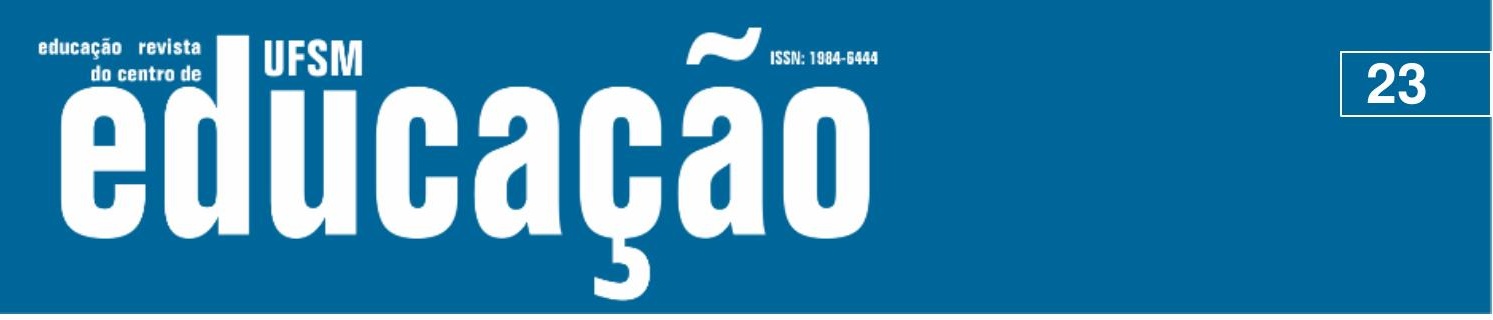

ISSN: 1984-6444 | http://dx.doi.org/10.5902/1984644439190

QUIJANO, Anibal. Colonialidad y modernidad/racionalidad. In: BONILLA, Heraclio (compilador). Los conquistados: 1492 y la población indígena de las América. Quito: Tercer Mundo-Libri Mundi Editors, 1992. p. 447.

SANTOS, Boaventura de Sousa; MENESES, Maria Paula. (Orgs.). Epistemologias do Sul. São Paulo: Editora Cortez. 2010. 637p.

SARTORELLO, Stefano Claudio. Milpas Educativas para el Buen Vivir. In: IV SEMINÁRIO INTERNACIONAL SOCIEDADE E FRONTEIRAS (IV SISF), II encontro internacional "laboratórios socionaturais vivos e roças educativas", Ins anais do caderno de resumos, Boa Vista, Universidade Federal de Roraima UFRR, 2018. p. 121-122.

SARTORELLO, Stefano Claudio. Conflito, colaboración y co-teorización en un proceso intercultural de deseño curricular en Chiapas. 2013. Tesis(Doctorado). Universidad Ibero Americana, Mexico.

TURNER, Terence. Da Cosmologia à Ideologia: resistência, adaptação e consciência social entre os Kaiapó. In: SIMPÓSIO "PESQUISAS RECENTES SOBRE A ETNOLOGIA E HISTÓRIA INDÍGENA NA AMAZÔNIA", patrocinado pela Associação Brasileira de Antropologia no Museu Goeldi (tradução de David Soares; revisão de Sylvia Caiuby Novaes), 1987.

WALSH, Catherine. Interculturalidad crítica y educación intercultural. In: UZIEDA, Jorge Viaña; MEALLA, Luís Tapia; WALSH, Catherine. Construyendo Interculturalidad Crítica. La Paz: III-CAB, 2010. p. 75-96.

WALSH, Catherine. Interculturalidade crítica e pedagogia decolonial: in-surgir, reexistir e re-viver. In. CANDAU, Vera Maria (Org.). Educação intercultural na América Latina: entre concepções, tensões e propostas. Rio de Janeiro: 7 Letras, 2009. p. 12-43.

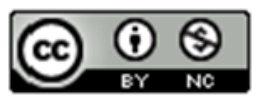

This work is licensed under a Creative Commons Attribution-NonCommercial 4.0 International (CC BY-NC 4.0)

\section{Notas}

\footnotetext{
1 Resultante da Pesquisa de Pós-Doutorado realizado no Programa de Pós-Graduação em Educação da Universidade Católica Dom Bosco (UCDB), sob a supervisão da profa Dra. Adir Casaro Nascimento e em parceria com o Centro de Investigaciones de Estudios Superiores em Antropologia Social (CIESAS), unidade Distrito Federal, México, sob a supervisão da profa. Dra. María Bertely Busquets. Financiada pelo Programa Nacional de Pós-Doutorado/PNPD/CAPES.
}

${ }^{2}$ Informamos que este artigo não consta as entrevistas que fizemos com os professores mexicanos, por isso, não submetemos o documento suplementar de aprovação em Comitê de Ética brasileiro. Ainda informamos que no 


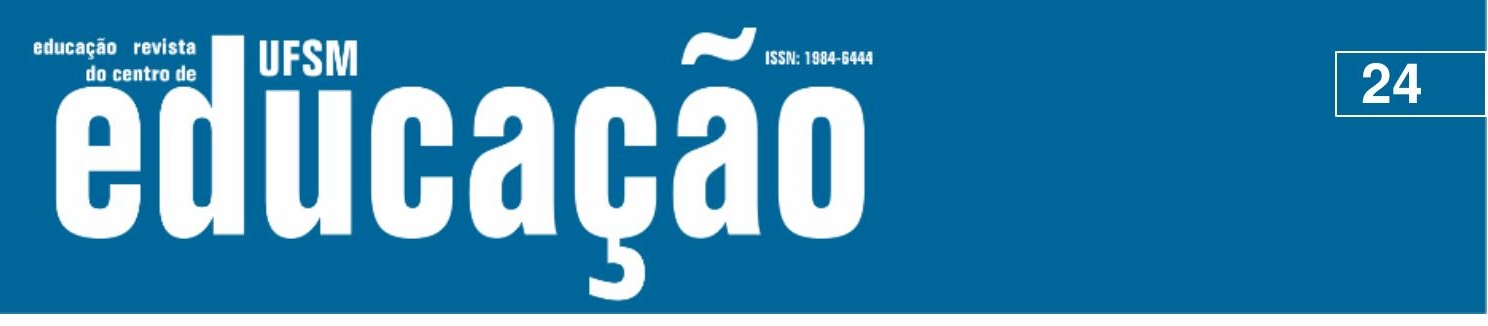

ISSN: 1984-6444 | http://dx.doi.org/10.5902/1984644439190

México não tem uma política clara acerca de realizar pesquisas com seres humanos, nesse sentido, naquele país as pesquisas com seres humanos não passam por nenhum Comitê de Ética. Mas, nós prezamos pela ética neste escrito.

${ }^{3}$ Essa expressão está elaborada no sentido de educação diferenciada na tese: DA SILVA, L. J. (2016) As contribuições do Método Indutivo Intercultural para a construção da Escola Indígena Diferenciada. 2016. (Doutorado) - Faculdade de Educação, Universidade Federal de Minas Gerais.

${ }^{4} \mathrm{O}$ termo 'Milpa' na tradução literal da língua espanhola para língua portuguesa significa 'roça', porém, não nos parece uma formulação mais apropria para o contexto brasileiro, porque muitos povos indígenas não trabalham com roças, no sentido tradicional dessa atividade produtiva. Fizemos algumas formulações, porque é por meio delas que compreendemos o ensino e a aprendizagem no território, como mencionamos com atividades produtivas e o que a ela se interliga (como rituais para a boa colheita). Assim, com essa formulação entendemos esse espaço como formativo e que produz epistemes, talvez uma aproximação da concepção de 'território educativo', no contexto indígena, e ainda no sentido de realizar atividades sociais como contribuição para o educar-se nesse espaço de formação. Outra formulação realizada no projeto mexicano encontramos no site: https://www.researchgate.net/project/Milpass-Educativas-Laboratorios-socionaturales-vivos-para-el-Buen-VIvir.

${ }^{5}$ Neste artigo chamaremos, por vezes, o projeto somente de 'Milpas Educativas'.

${ }^{6}$ Segundo o professor Stefano Sartorelo da UIA (2018) - que coordena conjuntamente com a professora Maria Bertely do CIESAS-o projeto das Milpas Educativas, é um financiamento promovido pela Fundação W.K. Kellogg. Esse projeto é de prosseguimento "político-educativo" dos denominados Diplomados Articulados chamados: Explicitación y Sistematizacióndel Conocimiento Indígena y Diseño de Materiales educativos interculturales y Bilingües, que impulsiona as atividades dos professores da UNEM/EI em conjunto com as universidades, nas escolas ou fora dela (Da SILVA; SARTORELLO, 2018; DA SILVA. 2016).

${ }^{7}$ Centro de Investigação e Estudos Superiores em Antropologia Social.

${ }^{8}$ Rede de Educação Indutiva Intercultural, REDIIN, que faz parte no âmbito da componente Diseño de Materiales Educativos Interculturales y Bilingues desenvolvido BAJO LA COORDINACIÓN DE LA DRA. MARÍA BERTELY BUSQUETS do Laboratorio Lengua y Cultura Víctor Franco (LLCVF), Centro de Investigaciones de Estudios Superiores em Antropologia Social (CIESAS), unidade Distrito Federal, México. A REDIIN, foi articulada em 2010, tem por finalidade impulsionar e promover atividades e iniciativas para consolidar uma Rede de Pesquisa e de Formação de Docentes Indígenas, buscando o propósito da interaprendizaje entre indígenas. Assim, a formação dessa Red abarca a pesquisa colaborativa, visando fazer convergir os interesses em comum dos professores, em consonância com as demandas educativas das suas comunidades e, entre suas finalidades, estão as de viabilizar trocas de experiências dos diferentes professores mexicanos envolvidos com essa proposta educativa e, ao mesmo tempo, constituir-se como um espaço para a formação dos mesmos na perspectiva do Método Indutivo Intercultural (SARTORELLO, 2018, p. 57; DA SILVA, 2016).

9 Esse projeto é um desdobramento a partir dos Diplomados Articulados chamados: Explicitación y Sistematizacióndel Conocimiento Indígena y Diseño de Materiales educativos interculturales y Bilingües. No projeto das Milpas Educativas, os ex-diplomantes da quarta geração se tornaram professores formadores, coordenado pela Dra. María Bertely e o Dr. Stefano Sartorello, em convênio entre a Universidade Iberoamericana e o Centro de Investigaciones y Estudios Superiores en Antropología Social. Ver mais informações em (DA SILVA, 2016).

${ }^{10}$ Para Bertely (2015) é o aprendizado do/no território, que diz que os conhecimentos, as habilidades e técnicas são “fomentada pelo processo de 'alfabetização territorial, ecológica' e que são impulsionados nos territórios socionaturais” (BERTELY, 2015, p. 2, tradução livre).

${ }^{11}$ Nota do caderno de campo.

$12 \mathrm{O}$ que inspirou os grupos da UFMG e UFRR começarem a experimentar essa formação com os professores indígenas foi inspirado nas experiências pregressa do México com o Método Indutivo Intercultural. Vale dizer, que aqui no Brasil, ainda estamos em estágio embrionário de estudos e desenvolvimento dessa experiência no Brasil, também em projeto de pesquisa.

13 Tradução: oficina. 


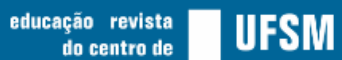

ISSN: 1984-6444 | http://dx.doi.org/10.5902/1984644439190

\footnotetext{
14 Tradução: I oficina Regional Intensiva.

${ }^{15}$ Podemos entender Foto-voz como um recurso fotográfico de produção de dados, portanto, neste caso, o lócus de enunciação foi fotografado à medida que os participantes consideravam importante o registro, para que mais adiante as fotografias ajudassem também na percepção do que revelavam também as entrevistas e auxiliar na explicação de sentimentos e inquietações, olhados a partir da "voz" dos participantes do espaço formativo (Cf. MELLEIRO, 2005).

${ }^{16}$ É dessa maneira que são chamados os professores indígenas que trabalham com as Milpas Educativas.

17 Entendemos o termo "tornadas próprias" quando um elemento vem do exterior da comunidade e nela é transformada com as práticas culturais de uma dada comunidade, assim, ela articula dois saberes/conhecimentos: o de fora e o de dentro da comunidade. E, por vezes, somente naquela comunidade dado elemento é trabalhado ou consumido de uma forma própria.
} 